\title{
FORMAÇÃO DE DOCENTES PARA A EDUCAÇÃO DE JOVENS E ADULTOS: REFLEXÕES SOBRE A EXPERIÊNCIA DO PIBID INTERDISCIPLINAR
}

\author{
Jaqueline Ventura ${ }^{\mathrm{i}}$ \\ Dayana Gomes ${ }^{\text {ii }}$ \\ Daniel Ferreira ${ }^{\text {iii }}$
}

\begin{abstract}
Resumo: O presente artigo tem por objetivo apresentar e refletir sobre a experiência de formação docente para EJA no âmbito do Programa Institucional de Bolsa de Iniciação à Docência da Faculdade de Educação da Universidade Federal Fluminense, nas áreas de História e Geografia. O Subprojeto Interdisciplinar: Formação de Docentes para a Educação de Jovens e Adultos realizou-se no Colégio Estadual Guilherme Briggs, em turmas de EJA de nível médio, nos anos 2014-2015. Tendo por referencial teórico a interdisciplinaridade referenciada no trabalho como princípio educativo e nas contribuições da pedagogia histórico-crítica, o relato discute as possibilidades de uma prática interdisciplinar na escola pública no desenvolvimento de ações que respeitem as características próprias do educando trabalhador.
\end{abstract}

Palavras-chave: Educação de Jovens e Adultos. Interdisciplinaridade. Formação de Professores.

\section{FORMATION OF TEACHERS FOR THE YOUTH AND ADULT EDUCATION: REFLECTIONS ABOUT THE EXPERIENCE OF INTERDISCIPLINARY PIBID}

\begin{abstract}
The present article has for objective to present and to contemplate about the experience of educational formation for EJA in the extent of the Institutional Program of Bag of Initiation to the Teaching of University of Education of the Fluminense Federal University, in the areas of History and Geography. Interdisciplinary Subprojeto: Formation of Teachers for the Youth and Adult Education took place at the State School Guilherme Briggs, in groups of EJA of medium level, in the years 2014 -2015. Tends for theoretical referencial the interdisciplinarity in the work as educational beginning and in the contributions of the pedagogy historical-critic, the report discusses the possibilities of an interdisciplinary practice in the public school in the development of actions that they respect the hard-working student's own characteristics.
\end{abstract}

Keywords: Youth and Adult Education. Interdisciplinarity. Formation of Teachers.

\section{Introdução}

O panorama da Educação de Jovens e Adultos (EJA) revelado pelas estatísticas oficiais evidencia uma elevada demanda por educação e a sua desigual distribuição, observada no 
afunilamento do número de estudantes à medida que aumenta o nível de ensino. De acordo com o IBGE/Pnad, o tempo médio de estudos do brasileiro é de 7,7 anos, ou seja, inferior ao tempo exigido para a conclusão do Ensino Fundamental. A taxa de analfabetismo da população brasileira com 15 anos ou mais, registrada em 2014, foi de 8,3\%, sem considerar o imenso contingente de analfabetos funcionais ${ }^{i v}$. Esse cenário de baixa escolaridade indica o quanto ainda está distante a universalização do Ensino Fundamental.

De acordo com o Censo Escolar de 2015, de 38,6 milhões de matrículas na Educação Básica na rede pública estadual e municipal, apenas 6,7 milhões se realizaram no Ensino Médio regular. Além disso, desse total, em média $41 \%$ dos alunos matriculados no Ensino Fundamental não o concluem. E cerca de 22 milhões de pessoas, com 18 anos ou mais, não concluíram o Ensino Médio. Para o estado do Rio de Janeiro, a estimativa é de 2 milhões de pessoas, com a ínfima taxa de atendimento da EJA no Ensino Médio de 7\%. Esses dados, por si sós, evidenciam o porquê de a defesa do direito à educação ser uma das principais bandeiras de luta do campo da Educação Popular e da Educação de Jovens e Adultos.

É importante contextualizar que a origem e a trajetória da Educação de Jovens e Adultos no Brasil são marcadas por características articuladas. A vinculação da EJA às frações mais empobrecidas da classe trabalhadora explica muito da sua tradição histórica marcada por características como: ações paralelas ao sistema regular de ensino, alvo de políticas descontínuas e de iniciativas aligeiradas. "De modo geral, persistem os velhos vícios: a permanência da alfabetização isolada da educação básica, a concepção de ensino supletivo e de ensino regular noturno, a improvisação de recursos materiais e humanos nas escolas etc." (VENTURA, 2011, p. 92). Essas marcas históricas traduzem a hegemonia de um projeto de sociedade no qual a universalização da educação, como direito humano fundamental, não é prioridade.

Assim, a despeito de a EJA ser concebida legalmente como direito à escolarização -ou seja, como direito aos ensinos Fundamental e Médio, independentemente da idade -, constatase que, em geral, ela é ignorada ou relegada a segundo plano tanto pela política educacional, dos vários níveis de governo, quanto pelos cursos de formação docente, na maioria das universidades. Fato é que a EJA ainda não é plenamente reconhecida como direito, como consta da legislação desde a aprovação da Constituição de 1988, passando pela LDB/1996 e reafirmada no Parecer 11/2000, que não é cumprido e segue sendo secundarizado por grande parte dos gestores públicos. 
Embora as mudanças não advenham somente da legislação, as conquistas no plano formal em relação à EJA são importantes, sendo as próprias leis fruto da correlação de forças em um dado momento histórico e, portanto, parte de um conjunto de lutas em defesa dos direitos humanos. Na difícil trajetória da Educação de Jovens e Adultos pelo seu reconhecimento enquanto política pública de educação - que deve ser com qualidade social e na perspectiva da educação emancipadora -, há ganhos legais que precisam ser recorrentemente reafirmados e reivindicados.

Dentre eles, destaca-se o reconhecimento na legislação da necessidade de Formação de Professores específica, a fim de respeitar as características próprias dessa modalidade da educação básica. Assim, embora formalmente compreenda-se a necessidade de formação docente para a EJA, estudos apontam (DI PIERRO, 2010; PORCARO, 2011; entre outros) que, de maneira geral, pouco ou nada se discute nos cursos de formação de professores, especialmente nas licenciaturas. Em suma, "embora as conquistas no plano formal sejam fundamentais, resultado da luta dos professores e movimentos sociais, vários estudos têm destacado o silêncio existente nos cursos de licenciatura em relação à EJA, em que pese a complexidade dessa modalidade" (VENTURA; BOMFIM, 2015, p. 214). Fica nítida, portanto, a necessidade de ações comprometidas com o desenvolvimento de uma formação que prepare o futuro docente, ou mesmo os professores já habilitados, para o trabalho na Educação de Jovens e Adultos, levando em conta as suas especificidades.

Essa é a intenção do "Subprojeto Interdisciplinar: Formação de Docentes para a Educação de Jovens e Adultos", um trabalho que envolve atividades de ensino, pesquisa e extensão desenvolvido no âmbito do Programa Institucional de Bolsas de Iniciação à Docência (PIBID), da Coordenação de Aperfeiçoamento de Pessoal de Nível Superior (CAPES). A formação docente no domínio da Universidade Federal Fluminense (UFF), em diálogo com as políticas de formação de professores do $\mathrm{MEC}^{\mathrm{v}}$, trouxe, através da execução do PIBID - ao menos no plano formal -, uma visibilidade maior da docência no espaço da universidade e o estímulo a projetos com a rede pública de ensino. Este programa apresenta-se como instrumento mediador entre a educação superior e a educação básica visando a contribuir para a formação do futuro professor, que pode vir a atuar tanto no ensino regular como na modalidade de Educação de Jovens e Adultos.

Nesse cenário mais amplo do MEC e da UFF, a Faculdade de Educação, por sua vez, desenvolveu nos anos de 2014 e 2015 no Colégio Estadual Guilherme Briggs (CEGUIB), em 
turmas da EJA do Ensino Médio, um trabalho que objetivou, de forma ampla, concorrer para o desenvolvimento de ações interdisciplinares na escola/EJA que contribuíssem para a superação da fragmentação do conhecimento e qualificassem as práticas educativas, pretendendo, ainda, colaborar com o aperfeiçoamento da formação docente inicial dos licenciandos e também da formação continuada da coordenadora, dos supervisores e dos demais docentes interessados.

Este $_{\text {artigo }}{ }^{\mathrm{vi}}$ tem por objetivo apresentar, e refletir, essa experiência, fruto desse trabalho coletivo de formação docente, que contou com uma equipe composta por uma coordenadora e dez licenciandos da UFF - envolvendo também, durante o período em que foi possível, duas bolsistas de Pedagogia- e pelos professores de História e de Geografia da rede pública estadual de educação do Rio de Janeiro, além da colaboração da professora da sala de leitura e da

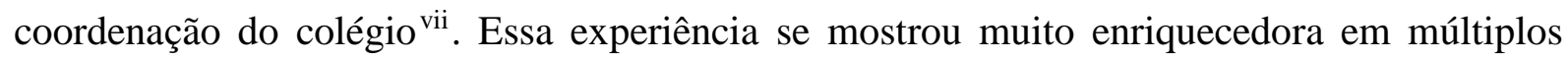
aspectos, dentre eles, pela vivência da docência como ação concomitante de ensinar e estudar, pela organização dos conteúdos intencionalmente vinculados às questões sociais, políticas, históricas e culturais, bem como pelo trabalho regular com os professores da Educação Básica que atuam na EJA na rede pública - o que tem permitido o desenvolvimento de ricas experiências entre professores e futuros professores, entre espaços escolares e acadêmicos.

\section{O Subprojeto Interdisciplinar}

Fundamentado teoricamente nos pressupostos da Pedagogia Histórico-crítica e da interdisciplinaridade centrada no trabalho como princípio educativo (MARX, 1980; SAVIANI, 1994, 1997; GASPARIN, 2002; CIAVATTA, 2015; entre outros), bem como na busca permanente de um processo integrador dos diferentes saberes, o Subprojeto Interdisciplinar intentou ultrapassar concepções e práticas conformadoras à ordem, articulando a EJA à luta por transformações sociais.

Nesse Subprojeto, estudantes de licenciatura de História e de Geografia atuaram, com bolsa de iniciação à docência, em turmas de EJA de um Colégio da rede estadual, especificamente nas turmas de NEJA1 ${ }^{\text {viii }}$, compartilhando com professores e estudantes o esforço de realizar uma prática interdisciplinar na escola pública que compreenda o lugar sociohistórico ocupado pelo estudante da EJA e possibilite a necessária "tomada de consciência sobre seu efetivo lugar no mundo social” (MENDONÇA, 2004, p.10). 
Pelo nosso entendimento, a interdisciplinaridade é a busca por articulações que auxiliem no desenvolvimento da compreensão dos fenômenos na totalidade social que os constitui, ou seja, concebendo-os como resultado da produção social do ser humano em determinado contexto, em múltiplas relações e em complexos processos sociais (CIAVATTA, 2015). E quando essa busca de articulações se baseia no trabalho como princípio educativo, as contradições das relações sociais de produção e o caráter histórico do processo de elaboração do conhecimento se revelam, permitindo ao estudante, que é também trabalhador, reconhecerse como sujeito capaz de lutar contra sua própria alienação e exploração, bem como pela transformação social. Do mesmo modo, compreendemos que o trabalho como princípio educativo é tomado aqui como princípio ético-político a fim de educar jovens, adultos e idosos da classe trabalhadora para uma visão crítica do mundo.

Nessa organização, as reuniões realizadas ordinariamente nas tardes de segunda-feira, com toda a equipe do subprojeto, alternadamente na escola e na UFF, tinham por objetivo o debate de ideias, o estudo de textos e o planejamento coletivo de aulas e outras atividades pedagógicas, bem como o de acompanhar o andamento do trabalho em sala de aula e o desenvolvimento de outras ações. Para o nosso planejamento, consideramos as sugestões de plano de unidade de Gasparim (2007) e, a partir dessas sugestões iniciais proposta pelo autor, fomos problematizando os conteúdos que compõem o Programa Nova EJA e o currículo mínimo proposto pela Secretaria de Educação, articulando-os com os textos estudados e, assim, fomos elaborando uma nova matriz curricular histórico-geográfica em fecundo diálogo com filosofia e sociologia. Primeiramente, planejávamos o que seria compartilhado no semestre como um todo, através de um plano de unidade, e depois as aulas, diária e interdisciplinarmente, sem deixar que as matérias ficassem esvaziadas de seus conteúdos, mas que se encontrassem e dialogassem possibilitando estabelecer "estudos de geografia humana para o desenvolvimento da antropologia e a superação da dicotomia espaço x tempo" (FAZENDA 1995, p. 18-20 apud CIAVATTA, 2015, p. 63).

No que se refere à participação na sala de aula, os licenciandos participaram das aulas às segundas e às quartas-feiras, no turno da noite. Pela nossa proposta de trabalho, as disciplinas envolvidas (história e geografia) seriam oferecidas nesses mesmos dias da semana (às segundas e às quartas-feiras), para que no primeiro dia pudéssemos ter quatro aulas dadas em dupla e no segundo cada disciplina dada separadamente, reconhecendo a particularidade de cada disciplina. 
Assim, com o intuito de assegurar um trabalho coletivo, a partir da contribuição das diferentes áreas do conhecimento, tendo por base o aporte teórico-metodológico que nos é oferecido pela categoria totalidade ${ }^{\mathrm{ix}}$, iniciávamos o trabalho com os educandos, a cada semestre, discutindo o significado e a centralidade do trabalho na vida do homem, além de explicar sobre o desejo de um trabalho conjunto entre universidade e professores da rede pública que atuam na EJA. Nossa prática pedagógica vivenciada na EJA procurou garantir o cumprimento da legislação que, acertadamente, vincula ao conteúdo o estudo da história e cultura afro-brasileira e indígena (Lei n. 11.645/2008).

Por ser uma corrente pedagógica de grande importância para a educação brasileira, a pedagogia histórico-crítica evidencia um método diferenciado de trabalho pedagógico que parte da prática social dos estudantes e dos professores, problematizando-a, oferecendo novos instrumentos para a análise e a formulação de uma nova síntese e retornando à prática social com um olhar renovado. Essas fases constituem o processo de construção do conhecimento nessa pedagogia, que é histórica, por entender que a educação é um dos fatores que interferem na sociedade, e pode por isso contribuir para a sua transformação; é crítica, por também saber da determinação que é exercida pela sociedade sobre a educação (GASPARIN, 2002).

Nesse sentido, a luta por uma educação contra-hegemônica que vise ao reconhecimento do outro e ao diálogo entre diferentes grupos sociais e culturais, de maneira igualitária e não hierárquica, é essencial para se desconstruir referenciais balizadores e preconceituosos e para avançarmos na educação tendo como horizonte a emancipação humana (MARX, 1980). Marcada pelas contradições que atravessam a nossa sociedade, a EJA é "alvo permanente de correlações de força que se materializam no âmbito da escola, mas a transcendem como expressões das lutas, disputas e contradições que marcam a injusta sociedade brasileira" (VENTURA; RUMMERT, 2015, p.119).

\section{O Colégio e os estudantes da EJA}

O Colégio Estadual Guilherme Briggs (CEGUIB) localiza-se no bairro de Santa Rosa em Niterói no estado do Rio de Janeiro. O contexto socioespacial do colégio é marcado pelos contrastes que envolvem o seu bairro, que fica próximo a Icaraí, considerado área nobre da cidade, que sofre grande especulação imobiliária e, por isso, os moradores mais empobrecidos são induzidos a se retirarem da área ${ }^{\mathrm{x}} \mathrm{e}$, ao mesmo tempo, é rodeado por comunidades 
conflituosas que formam o Complexo do Viradouro ${ }^{\mathrm{xi}}$ que, com o passar dos anos, tornou-se uma área maior e mais violenta. Hoje, o colégio é um espaço de fronteira que simbolicamente representa a linha divisória nesse processo de reorganização do bairro.

O CE Guilherme Briggs, inaugurado em 1914, é uma escola centenária que, assim como o seu contexto socioespacial, mudou ao longo de sua história. Hoje, ela oferece o segundo segmento do Ensino Fundamental e o Ensino Médio (regular e na modalidade EJA), atendendo em torno de 700 alunos, com aproximadamente 70 deles matriculados na EJA. O colégio conta com uma boa infraestrutura, que pode ser considerada uma das melhores da rede, possuindo, além das salas de aula e das dependências administrativas, sala multimídia, sala de leitura (biblioteca), auditório, refeitório, quadra de esporte, laboratório de ciências e laboratório de informática.

A maioria dos estudantes da EJA no CEGUIB é de negros, jovens e moradores de Santa Rosa. Em alguns casos, a escola foi escolhida não pela proximidade com a moradia, mas por ser próxima do trabalho do estudante. Embora o colégio conte com a boa infraestrutura citada, a maior parte desses espaços são pouco ou não utilizada pelos estudantes da EJA. A maioria dos estudantes tem alguma atividade de trabalho (formal ou informal) e em muitos casos chega a trabalhar mais de quarenta horas por semana ganhando em média um salário-mínimo. Essa excessiva carga horária causa grande impacto na disponibilidade de tempo para estudar fora do horário escolar. Esses alunos abandonaram a escola em sua maioria para ajudar a família, e geralmente seus pais também não concluíram o Ensino Fundamental demonstrando a recorrência da situação.

Esses dados foram obtidos através de questionário semiestruturado por meio do qual se traçou o Perfil dos Educandos a fim de conhecer os modos de viver, de pensar, os hábitos culturais dos sujeitos. Os trabalhadores-estudantes jovens, adultos e idosos da EJA integram um conjunto extremamente diverso nos seus interesses e nas suas necessidades educacionais, mas todos têm em comum a privação do direito à educação, na idade socialmente estipulada e é a privação desse direito que une a todos os estudantes da EJA. Na perspectiva de uma educação problematizadora fica para nós professores o desafio de nos perguntarmos: "em que medida estamos atentos às particularidades e singularidades dos processos de produção da vida social; em que medida contribuímos para transformar as experiências percebidas e modificadas como experiências de classe"? (TIRIBA; SICHI, 2011, p. 269). 


\section{Formação Docente: práticas pedagógicas interdisciplinares na EJA}

Como dito, os dados acima expostos foram obtidos através do levantamento do Perfil dos Educandos, uma das nossas ações que consistiu na elaboração de um questionário composto por 61 questões utilizadas para entrevistar os discentes ${ }^{x i i}$. É um dos instrumentos que nos permitem ir além do conhecimento do aluno empírico, possibilitando-nos conhecer o aluno concreto $^{\text {xiii }}$ da EJA.

Levar em consideração o perfil dos educandos e entender o lugar que o trabalho ocupa na vida deles é fundamental para o desenvolvimento do trabalho pedagógico. É compreender que cada um já traz consigo os mais diversos conhecimentos adquiridos ao longo de sua vida e prática produtiva, mas que por vezes são desconsiderados quando o princípio educativo do trabalho é negado.

Buscando superar esse quadro, a realização do projeto Perfil dos Educandos da EJA é uma ferramenta que visou auxiliar os professores e a direção do Colégio na busca do desenvolvimento de uma metodologia que considerasse o estudante em sua integralidade de ser humano e ser social, assim como em sua especificidade de aluno trabalhador. Após realizar as entrevistas, as respostas foram tabuladas com a finalidade de produzir gráficos sobre as principais delas e, assim, conhecer o perfil do estudante da EJA no CEGUIB. Informações importantes como faixa etária da maioria dos discentes - a remuneração média, a carga horária de trabalho, o tempo de que dispõem para estudar, o que conhecem e pensam sobre a escola, entre outras - passam a ser conhecidas pelos professores e pela direção, podendo vir a contribuir com o Projeto Político Pedagógico.

No primeiro semestre de 2014 os dados do Perfil do Educando foram apresentados ao conselho de classe e discutidos com os docentes e com a equipe pedagógica, e no semestre seguinte a apresentação incluiu os discentes, articulando as discussões sobre condições de vida e necessidades da classe trabalhadora. Assim, em 2015, para potencializar a divulgação e o debate entre o perfil e os próprios estudantes, foi elaborado o Projeto de Produção Audiovisual, que pretendia registrar, por meio de um curta-metragem ${ }^{\text {xiv }}$, o trabalho produzido com o perfil, proporcionando que os estudantes pudessem contar suas histórias e, assim, dar vida aos dados levantados no perfil.

Foram realizadas oficinas de filmagens para introduzir o uso da aparelhagem de filmagem, em parceria com o Observatório Jovem/LIDE UFF, sendo um momento significativo 
de aprendizagem para os bolsistas, futuros professores. Concluídas as entrevistas, o material gravado passou por um intenso processo de edição. Após a finalização dessa edição, o resultado do curta-metragem foi apresentado à escola em uma confraternização realizada pela equipe PIBID, bem como os dados do Perfil, fotos das atividades desenvolvidas ao longo do ano com a turma, o catálogo de livros preparado durante o Projeto Sala de Leitura, e a fala de funcionários, docentes e discentes sobre a sua avaliação do trabalho realizado.

Se o Projeto Perfil nos permite conhecer os estudantes, outras ações do subprojeto desenvolvidas dentro e fora da sala de aula incentivam a ampliação da visão de mundo dos estudantes, ao discutir as inter-relações entre diversidade cultural e desigualdade social.

Uma delas está relacionada à literatura e muito contribui para ampliar a compreensão que o discente tem do social, de si mesmo e do outro, servindo de apoio para romper com os paradigmas da colonialidade (CASTRO-GOMÉZ, 2005), quando articulada com o conteúdo discutido em aula. Falamos aqui do Projeto "Oficina de Leitura Literária: Uma Janela para o Mundo" que procurou propiciar situações de ensino e aprendizagem que aprimorassem a leitura e a produção de textos orais e escritos. Buscou também construir uma articulação entre as disciplinas de geografia, de história e de literatura, almejando problematizar os conteúdos e potencializar uma educação direcionada à (re)construção cultural, socioespacial e política, de maneira a enriquecer o pensamento crítico e a colaborar para a leitura de mundo dos estudantes.

Uma das questões do questionário aplicado aos estudantes da EJA, sobre quais espaços da escola conhecem e quais mais frequentam revelou que boa parte dos alunos não frequentava a Sala de Leitura. Sobre as razões desse distanciamento, em conversa informal, muitos alegaram presumir que a mesma ficasse fechada, e outros julgavam que só era para ir lá quando o professor levasse a turma, e havia ainda um grupo expressivo que conhecia a sala, mas declarava escassez de tempo para visitá-la pois, geralmente, os estudantes chegam atrasados, jantam no refeitório e são orientados a ir para suas salas de aula.

A Sala de Leitura ficava aberta para consultas e empréstimos, das $17 \mathrm{~h}$ às $20 \mathrm{~h}$, três vezes por semana, contava com profissional qualificado e um rico acervo. Contudo, observamos que embora dispondo de muitas obras, o acervo não era conhecido e não havia uma proposta de dinamização desse acervo com a EJA, ou seja, uma proposta de uso da Sala de Leitura pela EJA. Assim, estabelecemos que para o diagnóstico dos professores de que era preciso aprimorar a leitura e a produção de textos orais e escritos dos jovens e adultos proporíamos um projeto que incluiria em sua estrutura o uso da Sala de Leitura. 
Os encontros da Oficina de Leitura Literária foram realizados como parte integrante da sala de aula. Aconteciam todas as segundas-feiras à noite, no início das aulas, durando cerca de 30 minutos. A proposta envolvia a leitura acompanhada de textos ou trechos de um dos livros previamente selecionados pelos bolsistas, comentários sobre a obra, o livre debate sobre o tema trazido e o estímulo ao empréstimo com a indicação de que a devolução deveria ocorrer pessoalmente pelo estudante na Sala de Leitura do Colégio, motivando, dessa forma, a aproximação e a ocupação desse espaço, com interesses e demandas próprias da EJA. Em 2015, como aprofundamento da seleção inicial citada, foi organizado um Catálogo da EJA com o objetivo de deixar para o colégio um produto que pudesse auxiliar outros professores do CEGUIB na escolha de livros para serem trabalhados com as turmas da EJA e assim incentivar os estudantes jovens e adultos, de todas as turmas/EJA, a frequentar mais a Sala de Leitura, bem como levar seus livros para ler em casa. A produção desse catálogo também foi uma das maneiras encontradas para difundir o Projeto de Leitura Literária para outras turmas que não participavam diretamente do Subprojeto. O Catálogo está organizado em oito categorias: Memória, Didáticos, Mobilidade/Migração, Cidadania, Sociedades Indígenas (Lei 11.645/08), Sociedades Africanas (Lei 10.639/03), Literatura e Formação histórico-geográfica e social do Brasil. Foram catalogados 645 títulos.

Em nosso trabalho compreendemos a leitura como uma prática social e, nesse sentido, nós a elegemos como eixo central, considerando, principalmente, o potencial dos textos literários para tornar o mundo mais compreensível. Assim sendo, o foco central é auxiliar a formação dos estudantes da EJA, através de um trabalho com esse eixo central como forma de dar significado a ela na sala de aula dessa modalidade de ensino e, assim, contribuir para a formação de sujeitos leitores para a vida como um todo ${ }^{\mathrm{xv}}$.

No dia a dia, nossa atuação incentivou a criação de textos e a ampliação da leitura, tanto em sala de aula como nas várias atividades desenvolvidas. Entre elas, destacam-se o Projeto ENEM, o Mural da EJA e o blog do Projeto. O conjunto dessas atividades complementou o trabalho desenvolvido em sala de aula e contribuiu, de uma maneira geral, para que os trabalhadores que estudam no Ensino Médio pudessem ler, produzir textos, refletir sobre o que escrevem, ampliar o vocabulário, ampliar seu repertório cultural, refletir sobre questões sociais e sobre a própria sociedade.

Embora simples essas três ações convergem para potencializar um ambiente de estudo na EJA, que de alguma forma pudesse motivar os alunos a acompanharem e debaterem as 
ciências humanas. Nesse horizonte, foi desenvolvido o Projeto ENEM com a intenção de auxiliar os estudantes que possuíam interesse em debater temas das ciências sociais recorrentes nesse exame, discutindo de forma ampla assuntos importantes dos dias atuais para o entendimento da sociedade e reforçando o conteúdo apreendido em sala de aula, ajudando os que prestarão o ENEM, mas superando a perspectiva preparatória e se constituindo como grupo de estudos permanente, aberto aos interessados em participar.

Outras duas ações complementares são o blog e o mural da EJA. Este último, que compõe um dos vários murais do CEGUIB e foi cedido pela direção ao subprojeto, é propício para a exposição das atividades colocadas em prática e excelente para divulgar informações. Assim, o Mural da EJA, ou seja, a construção de um mural específico para informações que possam interessar mais diretamente a jovens, adultos e idosos da EJA, colado na parede da escola, embora seja uma ação simples, contribuiu muito para a divulgação de informações sobre autores e obras lidos em sala, bem como sobre temas como saúde, emprego, além de notícias sobre educação, cultura e lazer, principalmente as que fossem gratuitas ou a preços populares.

No que tange ao blog ${ }^{x v i}$, este também teve por finalidade a difusão de informações, porém de maneira mais complexa e com a possibilidade de preservar todos os dados, e assim ter o registro do processo. Com um leiaute atrativo e indicações relevantes buscaram-se o diálogo e a interação não só com os educandos, mas também com qualquer pessoa interessada em conhecer o trabalho. Nele, encontram-se informações sobre os componentes e seus objetivos, resumos das aulas, materiais de estudo e bibliografia, entre outros.

Todas as ações citadas estiveram interligadas ao espaço da sala de aula, tornando a aprendizagem significativa a partir de um planejamento articulado das aulas, ações e dos projetos desenvolvidos. Com essa compreensão, as aulas foram construídas de forma a dialogar com a experiência e a visão de mundo do estudante da EJA e discutir, de forma ampla, com base em questões conceituais próprias das Ciências Sociais, as inter-relações - por exemplo, entre educação, diversidade e cultura -, oferecendo subsídios para a desconstrução de visões etnocêntricas e reafirmando a busca de diálogos com outras culturas.

Como exemplo vale citar as aulas referentes ao primeiro tópico do planejamento, denominado "Meu lugar no mundo", que tem por finalidade apresentar as diversas cosmovisões, aspirando a discutir as variadas interpretações sobre a origem do mundo e do universo.

A formação do mundo, do universo e da vida foi apresentada e debatida de diferentes maneiras, precisamente em cinco vídeos, cada um contando a seu modo como se deu "a 
criação"xvii . Essas aulas foram de suma importância por vários motivos. Geralmente é nosso primeiro contato com os estudantes da EJA que ingressaram no nível médio e a partir delas conhecemos algumas das suas opiniões e concepções de mundo.

Inicialmente os alunos têm dificuldade de aceitar essa proposta de atividade e dinâmica; a apropriação de conhecimentos científicos pelos estudantes, superando o senso comum, não é um processo fácil para alguns jovens e adultos. Muitos deles, os religiosos em particular, expressam dificuldades em relativizar as diferenças e demonstram elevados níveis de intolerância étnico-religiosas. A maior resistência surge com a percepção da criação do mundo, segundo a visão Yorubá, como representante de um dos grupos étnicos do continente africano. Então, propomos discutir o tema África como origem da humanidade, com o objetivo de desconstruir a visão pejorativa dos colonizadores sobre o continente africano, ainda tão arraigada nos estudantes e no espaço escolar. Felizmente, à medida que as aulas e os debates avançavam, os estudantes flexibilizaram, cada vez mais, as suas posições mistificadoras e abriram-se ao diálogo com as diferentes perspectivas culturais para a explicação míticoreligiosa e filosófico-científica do mundo.

Em outras aulas foi posta em discussão a construção desigual do Brasil. Para ilustrar as desigualdades socioeconômicas e espaciais, por exemplo, foram apresentadas, a partir de pinturas de Debret, as profissões no período pós-Abolição, sendo estas comparadas com as da atualidade, tendo como foco provocar um debate acerca das transformações do regime de trabalho no Brasil. Através dessas pinturas foi possível discutir a escravidão, o processo de luta pela liberdade e agência dos próprios escravos para a conquista da emancipação, sua marginalização dos mesmos pós-Lei Áurea, o racismo e a ação do homem como modificadora do espaço e das instituições. Os questionamentos sobre as mudanças e permanências lhes possibilitaram a reflexão sobre o caráter das mudanças e a importância da mobilização da classe trabalhadora para uma transformação estrutural da sociedade.

Em suma, conteúdos como diversidade cultural e desigualdade social e interculturalidade e educação, centrais nas ciências humanas, foram trabalhados por professores de história e geografia através de aulas regidas em dupla, acompanhados dos licenciandos, mediante um processo coletivo e interdisciplinar de organização e com aulas inspiradas na pedagogia histórico-crítica quanto ao processo materialista-histórico de construção do conhecimento. Tudo isso, com o uso de recursos diversos, como filmes, leituras variadas, slides, visitas, debates, entre outros, a fim de incentivar a desconstrução de preconceitos, a valorização 
e o respeito ao que é diferente, a elaboração coletiva e individual do conhecimento, o desenvolvimento da leitura literária e de mundo, a produção de cartazes e textos, a pesquisa dentro e fora da escola e a reflexão sobre a educação e, principalmente, sobre a sua própria realidade social.

\section{Limites e avanços: avaliando o percurso de formação}

Além da formação discente, esse trabalho coletivo nos permitiu o desenvolvimento de uma formação docente que se realizou desde o momento do contato com a educação escolar e suas problemáticas. Entende-se que essa formação deve compreender a vivência do ambiente escolar, o conhecimento das dificuldades e dos desafios da educação brasileira. Esse é um ponto importante do subprojeto: a possibilidade de reconhecimento da escola pública que, através de experiências reais e do exame das dificuldades encontradas, é desafiada a desenvolver coletivamente a sua prática compreendendo que o conhecimento sistematizado é expressão de necessidades sociais historicamente situadas, que ele se constrói por aproximações e que ele é resultado da nossa capacidade de desvelar o maior número possível de aspectos do cotidiano social, a fim de que este seja um instrumento a mais na transformação da realidade.

Entre as inúmeras dificuldades, a lógica mercantilista e meritocrática das medidas implementadas pela SEEDUC-RJ acentuou nos últimos anos a já difícil situação dos professores com baixos salários, com desvalorização profissional e más condições de trabalho. Devido a esses problemas, os docentes se veem obrigados a ampliar sua jornada de trabalho, atuando em diversas escolas e turnos, além de complementar com projetos remunerados externos, comprometendo sua autonomia e sendo induzidos a reproduzir o conhecimento através de materiais prescritivos, numa lógica de ensino na qual estes não participam do processo de produção do conhecimento ${ }^{\text {xviii }}$. Impõe-se a um só tempo enorme controle tecnicista sobre o fazer pedagógico, tanto da escola como dos professores, e uma brutal intensificação do trabalho desses profissionais. A política adotada "de cunho economicista" se compromete com as necessidades do mercado e seus ideais de empregabilidade e não com as necessidades pedagógicas e sociais de docentes e discentes.

A Secretaria Estadual de Educação elege um currículo fragmentado e mínimo para cada nível e modalidade. Nesse cenário, a realização de um trabalho coletivo e interdisciplinar é muito difícil, uma vez que toda a organização do tempo e do espaço tende a favorecer o 
isolamento docente e a divisão do trabalho na escola. Presenciamos na rede estadual fluminense uma política pautada predominantemente na lógica de ranqueamento, em que o Índice de Desenvolvimento da Educação Básica (IDEB) torna-se o centro da avaliação, do planejamento e do acompanhamento da SEEDUC, fundamenta-se naquilo que Saviani (2008) denomina de pedagogia neotecnicista, caracterizada por ações padronizadas com foco em resultados e metas de produtividade.

Em um contexto de crise econômica do Estado, a educação é um dos setores mais afetados com os cortes de gastos do governo, reduções no quadro de funcionários terceirizados, atrasos e parcelamento de vencimentos de docentes e equipe administrativa. A partir de gastos com megaeventos ${ }^{x i x}$, isenções fiscais a empresas privadas e da redução dos royalties do petróleo $^{\mathrm{xx}}$, a comunidade escolar passa por dificuldades que intensificam a precarização da educação pública estadual.

Outra consequência dessa política de desvalorização e burocratização é a não distribuição para todos os alunos da NEJA dos mais básicos recursos educacionais, como livros didáticos, bem como a não disponibilidade de recursos eletrônicos ou mesmo fotocópias. No CEGUIB a utilização de mídias audiovisuais fica restrita a uma sala especial que deve atender à demanda de todo o colégio, sendo necessário reservá-las com longa antecedência. A dificuldade de acesso a materiais pedagógicos na rede estadual, por muitas vezes, força o educador a utilizar recursos próprios a fim de dinamizar suas aulas.

Fator social não diretamente ligado à crise na educação - mas fruto de uma sociedade que vê na marginalização e na punição a solução para a continuidade de seu projeto de desenvolvimento -, a questão da violência ganha reflexos também no ambiente escolar. Conforme verificado, o CEGUIB encontra-se localizado próximo a áreas consideradas violentas, onde há o domínio do tráfico de drogas, ocorrendo frequentes operações policiais e confrontos entre facções rivais. Assim sendo, houve momentos em que a violência interrompeu o trabalho pedagógico. O clima de insegurança afeta estudantes, profissionais da educação e bolsistas de iniciação à docência, prejudicando a escola e seus estudantes.

Fora do ambiente escolar, mas essencialmente relacionada a este, a situação de crise econômica e de cortes financeiros destinados à educação na universidade é também preocupante. O programa PIBID/CAPES, neste primeiro semestre de 2016, recebe sucessivas declarações de representantes do governo federal informando redução de verbas destinadas ao programa, com previsões de cortes e reformulações. A primeira proposta concreta de 
reformulação do programa não mencionava a possibilidade de grupos interdisciplinares. Essa dificuldade, de foro mais grave, traz alguns embaraços à nossa perspectiva de continuidade. Nosso propósito é continuar a aprimorar práticas educacionais na EJA que, de um lado, propiciem uma formação inicial e continuada coerente, em que teoria e prática estejam articuladas de forma concreta, possibilitando o desenvolvimento da práxis educativa, e, de outro, incentivem o (re)conhecimento do aluno da EJA como trabalhador, e consequentemente produtor de saberes, ser social, portanto agente transformador e ser integral, que interage com o mundo de forma interdisciplinar e não fragmentada - sempre levando em conta nosso objetivo, que é partir da experiência pessoal e obter uma compreensão da realidade à luz do pensamento materialista-histórico.

Internamente ao grupo, outro aspecto que dificultou o desenvolvimento do trabalho foi a substituição de bolsistas de Iniciação à Docência. A constituição de um grupo comprometido com um trabalho como esse não se faz rapidamente, além da dificuldade de apropriação teórica no que tange ao conceito de EJA e ao conceito de interdisciplinaridade, pouco trabalhados na formação das licenciaturas. Assim, cada aluno bolsista que ingressava precisava ser inserido na proposta do Subprojeto Interdisciplinar e em suas inúmeras ações realizadas dentro e fora da sala de aula, ao mesmo tempo em que já estava participando do trabalho, muitas vezes sem que tivéssemos tempo de discutir concepções e aprofundar a fundamentação teórica, em geral nova para eles. Assim, seja pelo pouco envolvimento com o projeto, seja pela incompreensão de como trabalhar com a leitura literária numa perspectiva emancipatória, o certo é que, por vezes, percebíamos uma tendência a reduzir a atividade à divulgação dos livros da Sala de Leitura durante a aula, indicando os que abordassem o conteúdo trabalhado, ou a reduzir à ação de catalogar títulos relacionados ao conteúdo de história e geografia do Ensino Médio. Superar essa visão que esvazia e reduz o projeto é um desafio constante para nossa formação continuada.

O relato dessas dificuldades não elide o valor do Subprojeto Interdisciplinar, pelo contrário, a sistematização e a análise da experiência vivida fazem parte da nossa concepção de formação que busca relacionar teoria e prática no processo de formação docente.

Observamos, como contribuição deste trabalho, um maior desenvolvimento da escrita, uma maior proximidade desses alunos com a leitura literária e uma consequente ampliação do vocabulário, do repertório cultural, da compreensão do social e de si mesmo, tanto por parte dos discentes quanto dos futuros docentes envolvidos no processo de ensino-aprendizagem. Para os últimos é possível acrescentar também a importante aquisição de conhecimentos sobre 
a literatura e seus usos pedagógicos, bem como sobre o letramento literário na EJA. A avaliação realizada pela equipe é a de que a experiência da EJA no PIBID, em razão das características político-pedagógicas do Subprojeto Interdisciplinar, tem trazido contribuições relevantes, seja pela aproximação com a escola pública, compartilhando seus desafios e esperanças, seja pela percepção da ampliação do processo de formação. Observa-se que os alunos bolsistas valorizam a experiência que estão tendo na modalidade, reconhecendo suas especificidades e necessidades em termos de reflexão sobre a questão político-pedagógica da EJA.

Apesar de todas as dificuldades relatadas, o trabalho coletivo desenvolvido e sua intencionalidade mostraram uma alteração no ponto de chegada da prática educativa, pois ao final de 2015 os professores e estudantes da EJA avaliaram ter havido ganhos significativos de aprendizagem e ter sido uma experiência rica de potencialidades para educandos e educadores, como sinaliza a pedagogia histórico-crítica.

A fundamentação teórico-metodológica adotada deixa clara a direção educacional crítica que abraçamos em nossas ações. Por isso, cabe registrar que as ações e os projetos desenvolvidos pelo subprojeto Interdisciplinar na EJA receberam o apoio e o incentivo da unidade escolar. A integração entre bolsistas e funcionários, principalmente da biblioteca, assume um papel de destaque para o desenvolvimento e o sucesso do Projeto Sala de Leitura. O curta-metragem é um exemplo da relação de parceria entre a universidade e a escola. $\mathrm{O}$ apoio da comunidade escolar nas gravações dentro do ambiente escolar, as entrevistas concedidas por professores, funcionários, direção e alunos tiveram um papel fundamental para o sucesso do curta-metragem. O apoio em sua propagação foi de extrema importância, pois este acabou se tornando um grande evento acolhido pela escola e pelos familiares dos estudantes. A divulgação do Projeto ENEM garantiu a sua execução, permitindo o ingresso dos participantes em instituições públicas de ensino.

\section{Considerações finais}

Este trabalho teve por finalidade sistematizar a experiência do Subprojeto Interdisciplinar: Formação de Docentes para a Educação de Jovens e Adultos, desenvolvido no âmbito do PIBID/CAPES/UFF. Conforme descrito, as atividades estiveram estruturadas em conceitos e ações que visaram a articular simultaneamente a formação docente e discente numa 
compreensão crítica da realidade educacional e político-social, em que prática e teoria estiveram conciliadas.

Ao considerar que o conhecimento acumulado está sempre em constante modificação, cabendo a cada um repensá-lo, transformá-lo, propor uma ação pedagógica interdisciplinar baseada no trabalho como princípio educativo, e oferecer aos estudantes as bases para a construção do "ser-sujeito" "xxi que, ao entenderem os diferentes mecanismos que interferem, modificam e controlam a sua prática, passam a dotá-la de sentido e direção visando à superação de uma realidade social de exploração.

Em relação à formação docente, expressou-se durante todo o texto a importância de uma prática pensada, da necessidade de associar de maneira coerente teoria e prática, de ultrapassar as barreiras de uma educação tradicional e intencionalmente sucateada. Pensar a atuação pedagógica nesse sentido global é de suma importância para a vivência profissional dos futuros docentes, pois lhes permite ultrapassar as conjecturas teóricas embasando-as com experiências práticas reais e não apenas imaginadas. Nesse sentido, as ações no âmbito deste Subprojeto e as leituras e os planejamentos a que estiveram articuladas possibilitaram uma preparação para o exercício docente, sobretudo na EJA. Redescobrir o ambiente escolar e vivenciar as dificuldades, geradas por uma política de educação que privilegia metas quantificáveis e não a qualidade do ensino conscientiza e motiva o licenciando a uma atuação empenhada na construção de um novo cenário, que passa pela ação política e também por um comprometimento perscrutador.

Além da articulação entre teoria e prática e da vivência do fazer pedagógico, compreende-se como elemento formativo para a EJA a elaboração coletiva e interdisciplinar do conhecimento. Planejar conjuntamente as atividades desenvolvidas com os licenciandos, os conceitos e problematizações necessários, os recursos a serem utilizados e as finalidades previstas não é tarefa fácil, mas é primordial para a superação da fragmentação e desarticulação do conhecimento observadas no ensino básico. Reconhecer que a Educação de Jovens e Adultos requer interação entre os diversos níveis de saber (representado no sistema escolar pelas várias matérias) e um planejamento coletivizado no qual prevaleça o diálogo é essencial para a promoção de uma educação de qualidade.

Na experiência de formação docente relatada neste artigo - em que universidade e escola pública compartilham tal formação e em que licenciandos e professores estudam e aprofundam seus conhecimentos e experiências pedagógicas -, as reuniões semanais foram o espaço 
reservado à reflexão e ao planejamento coletivo. Este espaço constituiu um dos componentes da formação inicial e continuada de professores. Entretanto, só foi possível concretizar esta formação para a atuação na EJA a partir do conhecimento da realidade da educação brasileira, da Educação de Jovens e Adultos em especial, e do estudante da EJA. Foi o que permitiu vislumbrar as dificuldades e as possibilidades da ação docente, bem como fazer uso da teoria de forma consciente e coerente para delinear os caminhos. Assim, a proposta de formação de professores para a EJA esteve vinculada a outra de ação pedagógica na EJA numa perspectiva interdisciplinar e histórico-crítica.

Ao registrar e refletir sobre essa experiência de formação docente pretendemos contribuir para o desenvolvimento da EJA como direito a uma modalidade de ensino que efetivamente cumpra a função reparadora, mas também para que possamos contribuir para a construção de uma nova identidade para a EJA, colaborando com a necessária mudança nas concepções político-pedagógicas que têm fundamentado a EJA nas escolas e na universidade.

\section{Referências}

BRASIL, Governo Federal. Ministério da Educação. Resolução $C N E / C E B n^{o} 1$, de 5 de junho de 2000. Estabelece as Diretrizes Curriculares Nacionais para a Educação de Jovens e Adultos. Brasília, 2000.

. Governo Federal. Ministério da Educação. Resolução $n^{o}$ 1, de 17 de junho de 2004. Estabelece Diretrizes Curriculares Nacionais para a Educação das Relações Étnico-Raciais e para o Ensino de História e Cultura Afro-Brasileira e Africana. Brasília, 2004.

. Governo Federal. Ministério da Educação. Resolução no 3, de 15 de junho de 2010. Institui Diretrizes Operacionais para a Educação de Jovens e Adultos nos aspectos relativos à duração dos cursos e idade mínima para ingresso nos cursos de EJA; idade mínima e certificação nos exames de EJA; e Educação de Jovens e Adultos desenvolvida por meio da Educação a Distância. Brasília, 2010.

CASTRO-GÓMEZ, S. Ciências sociais, violência epistêmica e o problema da "invenção do outro". In: LANDER, E. (Org.). A colonialidade do saber: eurocentrismo e ciências sociais: Perspectivas latino-americanas. Buenos Aires: Clacso, 2005.

CIAVATTA, M. A interdisciplinaridade e a formação integrada: exercício teórico ou realidade possível? In: . O trabalho docente e os caminhos do conhecimento: A historicidade da educação profissional. Rio de Janeiro: Lamparina, 2015. 
DI PIERRO, M. C. Balanço e perspectivas da pesquisa sobre formação de educadores/as de jovens e adultos. In: OLIVEIRA, E. F. et al. (Org.). III Seminário Nacional de Formação de Educadores de EJA. Porto Alegre, 2010.

FAZENDA, I. C. A. Integração e interdisciplinaridade no ensino brasileiro: efetividade ou ideologia. 6a ed. São Paulo: Loyola, 2011.

GASPARIN, J. L. Uma didática para a Pedagogia Histórico-Crítica. Campinas (SP): Autores Associados, 2002.

GONÇALVES, F. dos S.; ALBERTINI, R. A interdisciplinaridade centrada no trabalho como princípio educativo. Belo Horizonte: Trabalho e Educação, n. 3, 1998.

KOSIK, K. Dialética do concreto. São Paulo: Paz e Terra, 1995.

LA BARRE, J. Choque de futuro: o Rio dos megaeventos. In: O Social em Questão, Rio de Janeiro: PUC-Rio, Ano XVI, v. 1, n. 29, p. 43-68, 2013.

MARX, K. O Capital. Vol. I. Rio de Janeiro: Civilização Brasileira, 1980.

MENDONÇA, S. R. de. A atualidade - quase sempre omitida-do Marxismo: Reflexões sobre história e interdisciplinaridade. Niterói (RJ): Trabalho Necessário, 2004.

PORCARO, R. C. Caminhos e desafios da formação de educadores de jovens e adultos.186f. Tese (Doutorado em Educação) - Faculdade de Educação da UFMG, Belo Horizonte (MG), 2011.

SAVIANI, D. O Trabalho como princípio educativo frente às novas tecnologias. In: FERRETI, Celso João et alii (org.). Novas tecnologias, trabalho e educação: um debate multidisciplinar. Petrópolis (RJ): Vozes, 1994.

Pedagogia Histórico-Crítica: Primeiras aproximações. São Paulo: Editores Associados, 1997.

2008.

. A pedagogia no Brasil: história e teoria. Campinas (SP): Autores Associados,

VENTURA, J. A trajetória histórica da educação de jovens e adultos trabalhadores. In:

CIAVATTA, M.; TIRIBA, L. (Org.). Trabalho e Educação de Jovens e Adultos. Brasília: Líber Livro e Editora UFF, 2011, p. 57-97.

VENTURA, J.; BOMFIM, I. Formação de Professores e Educação de Jovens e Adultos: o formal e o real nas licenciaturas. In: Educação em Revista, v. 31, n. 2, p. 211-227, Belo Horizonte (MG), abril/junho de 2015.

VENTURA, J.; RUMMERT, S. Educação de Jovens e Adultos Trabalhadores: velhos "novos desafios" na política e na formação docente. In: VENTURA, J.; RUMMERT, S. (org.). 
Trabalho e Educação: análises críticas sobre a escola básica. Campinas (SP): Mercado de Letras, 2015. p. 103-124.

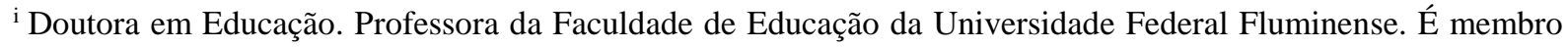
do Núcleo de Estudos Documentação e Dados em Trabalho e Educação (NEDDATE/UFF) e do Laboratório de Investigação, Ensino e Extensão em Educação de Jovens e Adultos (LIEJA/UFRJ). Bolsista Coordenador de Área PIBID/CAPES. Email: jaqventura@uol.com.br

ii Estudante do curso de História da Universidade Federal Fluminense, Bolsista de Iniciação à Docência PIBID/CAPES. E-mail: dayanamg@id.uff.br

iii Daniel Candido Ferreira, estudante do curso de Geografia da Universidade Federal Fluminense, Bolsista de Iniciação à Docência PIBID/CAPES. E-mail: dc2040@ hotmail.com

iv $\mathrm{O}$ IBGE considera analfabeto absoluto aquele que não sabe ler nem escrever um bilhete simples no idioma que conhece e analfabeto funcional o com baixa escolaridade, estima-se menos de quatro anos de estudo completos.

v Entre os programas da Capes voltados para formação de professores da educação básica, destacam-se: Prodocência, Observatório da Educação, PARFOR, LIFE e o PIBID. (Disponível em:
\end{abstract} http://www.capes.gov.br/educacao-basica)

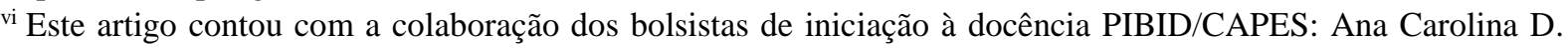
Aguiar; Ana Luiza Neves de Oliveira; Daniel Candido Ferreira; Dayana Monteiro Gomes; Gilson Cruz das Neves Júnior; Jéssica M. R. Santana; Jean Junior de Lima França e Keilla Gomes Giron.

vii Agradecemos aos professores-supervisores Paulo Roberto C. Ribeiro e Simone Antunes, bem como a professora da Sala de Leitura Vânia Poubel e a diretora geral Alcinéa Souza R. da Silva pelas contribuições durante a realização do Subprojeto.

viii Em 2013, o Programa Nova Política de Educação de Jovens e Adultos (Nova EJA ou NEJA), foi implementado na EJA de nível médio nos colégios estaduais. O Programa Nova EJA foi instituído pela Resolução 4951/2013 (cap.VI, art. 31 e 32) que impôs nova matriz curricular modular, elaborou e distribuiu o material didático e executou um programa específico de formação de professores. De acordo com essa Resolução, a NEJA "estruturase em 04 (quatro) módulos semestrais, totalizando 02 (dois) anos para a conclusão do Ensino Médio nesta modalidade" (Art.31); o tempo de aula será de 50 minutos, garantindo 1.200 horas, duração mínima para essa etapa de ensino. Os módulos se organizam por disciplinas, e as únicas ofertadas nos quatro módulos são Língua Portuguesa/Literatura e Matemática. As disciplinas voltadas para as ciências humanas e educação física, nos módulos I e III. Já as que fazem parte das ciências da natureza, mais Língua Estrangeira e Artes, nos módulos II e IV. A nova organização separou as Ciências Humanas e as Ciências da Natureza, oferecendo-as em períodos intercalados. É clara a primazia por português e matemática em detrimento das demais disciplinas. As aulas são ministradas por um professor em cada disciplina. A inclusão do professor na NEJA é por adesão e atuação concomitante no curso de formação oferecido pela Fundação Centro de Ciências e Educação Superior.

ix Para superar a aparência e compreender o real é imprescindível a busca das conexões para reconstituir a realidade concreta como um todo estruturado. Conforme esclarece Kosik (1995:36) "Da vital, caótica, imediata representação do todo, o pensamento chega aos conceitos, às abstratas determinações conceituais, mediante cuja formação se opera o retorno ao ponto de partida; desta vez, porém, não mais como ao vivo, mas incompreendido todo da percepção imediata, mas ao conceito do todo, ricamente articulado e compreendido. $\mathrm{O}$ caminho entre a 'caótica representação do todo' e a 'rica totalidade da multiplicidade das determinações e das relações' coincide com a compreensão da realidade".

x Por conta disso, Santa Rosa foi dividida em duas partes, uma, cujo nome é Jardim Santa Rosa, localiza-se ao lado de Icaraí e passou a ser uma extensão desse bairro mais abastado, com grandes prédios de classe média e uma oferta de serviços para o público desses condomínios; e a outra manteve o nome de Santa Rosa que é a parte cercada por favelas, mas não deixa de sofrer os mesmos processos que o Jardim Santa Rosa - entretanto, nessa parte as contradições são mais visíveis. 
${ }^{x i}$ Conjunto de comunidades que abrangem Viradouro, Beltrão, Souza Soares, Zulu, Matos Coutinho (Mascou) e União. O colégio, além de atender a essas comunidades mais próximas, também recebe alunos de comunidades como Vital Brasil, Atalaia, Chiqueirinho, Igrejinha, Sapê e Morro do Céu, localizadas nas outras regiões da cidade. xii As entrevistas são realizadas a cada semestre com a turma NEJA I, para manter os dados atualizados. Os questionários são preenchidos pelos bolsistas a partir do diálogo com os discentes, e cada bolsista fica responsável por entrevistar um por vez, com o intuito de não tornar a pesquisa superficial. O Perfil dos Educandos consiste num questionário de 61 questões, dividido em quatro grandes blocos: As informações pessoais dos alunos (idade, escolaridade dos pais etc.); relações com o trabalho; relações com a escola; e outras coisas de sua vida (como religião, formas de lazer etc.).

xiii Com explica Saviani, para o aluno concreto, enquanto síntese de relações sociais, é fundamental passar a visão de senso comum para uma visão articulada, de base científica e ter acesso a conteúdos (1997).

${ }^{\text {xiv }}$ Disponível em <https://www.youtube.com/watch?v=wGs-sQ-i5-Y\&feature=youtu.be>.

${ }^{\text {xv }}$ Trabalhar a leitura literária na perspectiva emancipatória da educação significa não atribuir-lhe um significado utilitarista (preparatório para mercado de trabalho etc.), nem simplista (apenas uma ferramenta para decodificação e desenvolvimento da escrita).

xvi Disponível em <http://pibidejainterdisciplinar.blogspot.com.br/>.

xvii Os recursos utilizados foram filmes e músicas. Assim, foram exibidos cinco vídeos de curta-metragem sobre a "Origem do Universo", são eles: 1- Visão científica: Big Bang. A Origem do Universo; 2- Visão Yorubá: A criação do mundo na mitologia Yorubá; 3- Visão cristã: Gênesis: Deus e a Criação; 4- Visão científica e filosófica: Marcelo Gleiser: A Nossa História da Criação; 5- Visão Grega: O mito da criação Grego. Além de músicas como: Meu pai oxalá, O canto de Oxum e Tatamirô (CD Pérolas de Toquinho e Vinicius) e Akekhoofana no Jesu (Música Gospel Africana). Disponível em <http://www.youtube.com/watch?v=G2NZ9zQ6oBg >.

xviii Os docentes vinculados à SEEDUC e à FAETEC iniciaram uma greve no mês de março de 2016.

xix “Ao longo da quase década 2007-2016, o Rio de Janeiro terá recebido quase um megaevento (esportivo ou não) por ano: Jogos Pan-americanos de 2007, FifaFanFest de 2010, Rock in Rio de 2011, Rio+20 de 2012 (ano em que o Rio entrou também no patrimônio da humanidade da UNESCO na categoria "Paisagem cultural"), Jornadas Mundiais da Juventude e Copa das Confederações ambas de 2013, Copa do Mundo de 2014, e finalmente o summum, as Olimpíadas de 2016" (LA BARRE, 2013, p. 44).

${ }^{x x}$ Disponível em: <http://g1.globo.com/economia/noticia/2016/01/arrecadacao-com-royalties-do-petroleo-cai25-em-2015.html>. Acesso em 02 de maio de 2016.

xxi Para um estudo importante sobre a autodescoberta do aluno como um "ser-sujeito" conferir Gonçalves; Albertini (1998). 